\title{
Entre el textil y el ámbar: las funciones psicosociales del trabajo artesanal en artesanos tsotsiles de la ilusión, Chiapas, México
}

\author{
Between textil and amber: the \\ psychosocial functions of the artisan work \\ made by indigenous artisans from a Tsotsil \\ community in La llusión, Chiapas, Mexico
}

Perla Shiomara Del Carpio Ovando

Universidad Complutense de Madrid

sonrisa155@gmail.com

\section{Resumen}

Esta investigación tiene como objetivo principal el estudio de las funciones psicosociales del trabajo artesanal que realizan artesanos indígenas de una comunidad tsotsil de Chiapas, México. Constata esta tesis que el análisis de las artesanías invita a reflexionar necesariamente sobre aspectos económicos en íntima relación con aspectos de índole cultural y psicosocial. Se defiende aquí que quienes se dedican a la producción de artesanías enfrentan múltiples dificultades dentro de las que sobresale la precariedad, el poco reconocimiento social, la discriminación y la exclusión. A pesar de ello, las artesanías contribuyen a la reproducción económica, social y cultural de quienes lo realizan, y constituyen elementos privilegiados en tanto vehículos de múltiples significados sociales, históricos y de pertenencia grupal, a través de los cuales es posible "rastrear" procesos de transformación social. Por ello, a la luz de los datos obtenidos en el trabajo de campo, esta tesis propone un modelo de las funciones psicosociales del trabajo artesanal indígena.

Palabras clave: Artesanías; Indígenas; Funciones psicosociales; Trabajo; Identidad

\section{Abstract}

The aim of this research is to study the psychosocial functions of the artisan work made by indigenous artisans from a Tsotsil community in Chiapas, Mexico. The analysis of handicrafts encourages reflection on economic aspects in intimate relation with cultural and psychosocial elements. It is argued that those who work on the production of handicrafts face many difficulties such as precariousness, little social recognition, discrimination and exclusion. Despite this all, handicrafts contribute to the economic, social and cultural reproduction of those who make them. Also, handicrafts are privileged elements as they are vehicles of multiple social, historical and group belonging meanings through which is possible to "track" processes of social transformation. Based on the findings obtained while conducting field work in Chiapas, a model of the psychosocial functions of the indigenous artisan work is proposed in this dissertation.

Keywords: Craftwork; Indigenous; Psychosocial functions; Work; Identity 


\section{¿Por qué vive el trabajo artesanal ${ }^{1}$}

Las artesanías forman parte de las múltiples fuentes de ingresos de las comunidades y también remiten a aspectos culturales que dan cuenta de la historia y de la representación simbólica de los pueblos que la producen (Balazote y Rotman, 2006; Rotman, 2002 y 2007).

Hay pues que considerar a la actividad artesanal como constitutiva de relaciones sociales (Novelo, 1976) y como un trabajo que remite a la economía, a la subsistencia, a la identidad y al patrimonio cultural de un grupo (Rotman, 2007). Por eso, las artesanías indígenas han resultado históricamente relevantes para el abordaje de los pueblos originarios. Los objetos que producen "hablan", de cierta forma, de quién las produce y cómo las produce.

Las artesanías tienen un componente de producción "tradicional", a la vez que son una estrategia económica de las familias indígenas. Además, como indica Sennett (2009), la artesanía comprende la cultura material y el conocimiento tácito como auténticos bienes de capital social, esto es, conocimientos y habilidades que se acumulan y se transmiten a través de la interacción social.

Hay que subrayar también que las artesanías casi siempre aluden a un contexto de origen rural con formas específicas de vida y constituyen elementos privilegiados en tanto vehículos de múltiples significados sociales, históricos y de pertenencia grupal, a través de los cuales es posible "rastrear" procesos de transformación social. Como indica Cardini (2007), las artesanías son parte de las estrategias económicas y a la vez medio de lucha y memoria, como continuo y transmisión de su cultura, en su historia de traslados y de búsquedas de "nuevos horizontes". Al mismo tiempo, son objetos de consumo que circulan en diversos espacios de comercialización, aspecto que determina transformaciones tanto en los materiales como en la cantidad y la calidad de trabajos investidos.

Señálese entonces que, por una parte, podemos encontrar el trabajo artesano que sirve para la supervivencia y del cual se obtienen ingresos y puede y debe considerarse como empleo (al implicar remuneración económica, es decir, tiene un valor económico que si bien no es un salario si son beneficios económicos que cumplen, de cierta manera, la misma función que el salario) y, por otra, podemos también encontrar trabajo artesanal que no entra en el mercado y que no tiene un fin instrumental sino de uso personal, doméstico, espiritual o ritual.

Tenemos así que en las artesanías convergen lo cultural y lo económico; los procesos identitarios y de memoria; lo tradicional y patrimonial y los debates con el arte (Cardini, 2007).Partiendo de lo anterior, podemos decir que la artesanía como actividad productiva, a la vez que objeto de consumo, está caracterizada por ser vehículo de distintos contenidos culturales e históricos que la disparan más allá y más acá de su carácter de mercancía que circula en distintos espacios de comercialización. En este sentido, el abordaje de las producciones artesanales debe contemplar la dimensión cultural, psicosocial y económica de manera complementaria y retomar los enfoques teóricos que proponen un estudio integral de los procesos de producción, circulación y consumo (García Canclini, 1982/1986; Novelo, 1976).

El abordaje que se realiza aquí de las artesanías las considera, pues, como un fenómeno simultáneamente de orden económico y simbólico. Se entiende a estos objetos como proceso y no como resultado (Novelo, 1976), ya que las artesanías deben ser vistas como proceso de producción que permite reproducir el modo de vida de quien los realiza. Al mismo tiempo, se trata de una actividad

\footnotetext{
${ }_{1}^{1}$ Agencia de patrocinio: Consejo Nacional de Ciencia y Tecnología (CONACYT, México).
} 
anclada en las tradiciones del pueblo que las elabora, aspecto que brinda particularidades. Esto implica la necesidad de focalizar el estudio no sobre los objetos artesanales sino en los procesos en que éstos son elaborados, circulan socialmente, y en los cuales se conforman sus significados (Rotman, 2001). Por eso es que hay que enfatizar que las artesanías traslucen, material y simbólicamente, los cambios que forman parte de la vida cotidiana de los productores, las transformaciones sufridas por su cultura y su contexto social y ambiental. Hay que contemplar los bienes artesanales como objetos que poseen para los pueblos originarios un contenido material y simbólico y contribuyen a su reproducción económica, social y cultural (Rotman, 2007).

\section{Apuntes metodológicos}

Dada la pluralidad de paradigmas, enfoques, perspectivas y técnicas de investigación resulta necesario considerar que la elección de la metodología está en función de los objetivos y del objeto de estudio. Este estudio se inclina con claridad hacia las aproximaciones cualitativas. Esta preferencia por los métodos cualitativos resulta comprensible dado a los objetivos de esta investigación: conocer, describir y analizar las funciones psicosociales del trabajo artesanal indígena y el contexto económico, social y cultural en el que esta producción se realiza.

Es, pues, éste un estudio cualitativo de tipo etnográfico cuyo trabajo de campo se ha realizado del verano del 2008 al verano del 2011. Las técnicas utilizadas han sido: la observación participante, la entrevista abierta y semiestructurada, la obtención de material audiovisual, el análisis de documentos y la elaboración de un diario de campo.

Se realizó este estudio en una comunidad tsotsil perteneciente al municipio de Simojovel de Allende, Chiapas, México. Esta comunidad está constituida -aproximadamente- por 400 habitantes, quienes se dedican al trabajo del campo, del hogar, de la construcción y a la producción de artesanías (especialmente textiles y ámbar).

Fueron entrevistadas 20 mujeres de tres generaciones: niñas, adultas y mujeres mayores, a la vez que también se obtuvo información de habitantes de la comunidad, de la región y de instituciones encargadas de las artesanías de Chiapas y del país.

Esta tesis también se une a los trabajos que utilizan las tecnologías de la información para su análisis. Por ello, se ha acudido aquí al software basado en la Teoría Fundamentada: Atlas.ti (versión 5.0). Esto ha sido así por considerarse este programa "una herramienta informática cuyo objetivo es facilitar el análisis cualitativo de, principalmente, grandes volúmenes de datos textuales" (Muñoz, 2005, p. 2). Fue allí donde se colocó, ordenó y analizó la transcripción de las entrevistas, y posteriormente se realizaron esquemas para presentar resultados.

\section{Algunos resultados: Funciones psicosociales del trabajo artesanal}

Son múltiples los temas que se abordan en el análisis de los resultados de esta tesis, sin embargo, únicamente se exponen aquí aquéllos que nos permiten conocer y reflexionar respecto a las funciones psicosociales del trabajo artesanal indígena. 


\section{Función instrumental del trabajo}

El trabajo es un instrumento para el logro de autonomía económica. Como medio de producción, distribución, consumo, de obtención de bienes y servicios permite la supervivencia e independencia no sólo de las personas a nivel individual, sino como motor de la economía global, es también articulador social (Álvaro, 2003). La primera función del trabajo es, por tanto, la de proveer de los medios necesarios para poder subsistir, he ahí su carácter obligatorio. La dimensión económica es el medio principal a través del cual la persona se relaciona con la sociedad y contribuye al mantenimiento de la misma (Álvaro, 1992). Permite la supervivencia, la emancipación, en definitiva, la independencia.

Por eso Pavlu (joven ambarero de La llusión) afirma que cuando tenga hijos le gustaría que éstos aprendieran el oficio artesanal para que tuviesen una fuente de ingresos. También por ello algunas niñas de la comunidad aunque no saben bordar quieren que las generaciones futuras aprendan el oficio y lo realicen no necesariamente para rescatar una actividad de antigua raigambre sino para aumentar las fuentes de ingresos familiares.

Ante la austeridad, la necesidad y la situación económica — de las familias de La llusión — sobresale el carácter instrumental del trabajo. Agulló (1997), en este sentido, explica que aunque el trabajo sea considerado como medio, el que siga en aumento una ideología de carácter instrumental de la actividad laboral, ello no significa, como defienden también otros autores (Álvaro, 1992; Blanch, 1986; Sanchis, 1991) que el trabajo esté perdiendo la centralidad para las personas. La actividad laboral es el eje sobre el que gira gran parte de nuestra vida. Hay que decir, entonces, que el trabajo, sigue siendo valorado positivamente y como valor central (Agulló, 1997) en la vida de las personas. Esto es válido para los habitantes de La llusión. Dígase también que además de proveer de recursos económicos realizar artesanías cumple otras funciones que a continuación deben detallarse.

\section{Funciones expresivas del trabajo}

El trabajo no tiene un valor periférico, servil o meramente instrumental en La llusión. Tampoco ha perdido su centralidad, sino todo lo contrario, pues tiene un valor central, integrador y expresivo. El trabajo supone, para varias mujeres, algo más que un simple medio de obtención de bienestar material pues es fuente de satisfacción personal, da sentido a la vida y ocupa un rango importante en la jerarquía de los valores socioculturales

A este respecto Agulló (1997) subraya el carácter del trabajo como institución social por medio del cual los individuos dan sentido a sus vidas, a la vez que satisfacen algunas de sus necesidades. De esta manera, el trabajo sigue actuando como categoría central y sigue estructurando y determinando experiencias vitales. De aquí que ahora tengamos que reflexionar sobre estas funciones expresivas del trabajo artesanal.

\section{Desarrollo de habilidades, destrezas y saberes}

Agulló (1997) reflexiona sobre las funciones positivas del trabajo o generadoras de bienestar psicosocial y subraya su función de proporcionar oportunidades para el desarrollo de habilidades y destrezas. En el caso del trabajo artesanal, es precisamente esta función (el desarrollo de la habilidad, que se explica por 
la dedicación y preparación desde la niñez) un motivo que para algunos autores (Morales, 2000; Ruiz y Trejos, 2000) es factor que permite la preservación del arte textil indígena.

Así, el trabajo artesanal permite y posibilita desarrollar y mejorar diversas habilidades y con ello el desarrollo de las capacidades personales. Su ejecución implica técnicas y movimientos corporales como la postura, el equilibrio, los movimientos manuales y la concentración visual, a la vez que también requiere habilidades cognitivas: atención, concentración, creatividad e imaginación. Con la ejecución de éstas, artesanos y artesanas se vuelven expertos en el trabajo que realizan en un dado espacio, contexto y tiempo.

\section{Desarrollo de una actividad: Distrae, ocupa y entretiene}

Han sido diferentes las perspectivas teóricas desde las que se ha destacado la importancia del trabajo en el desarrollo de una actividad. Hendrick (1943), por ejemplo, señala que el trabajo está asociado a la necesidad innata de desarrollo corporal e intelectual y añade a los principios de placer y realidad, el principio de trabajo en la explicación del desarrollo de la actividad humana. El trabajo, pues, ocupa a quien lo realiza y, en el caso de La llusión, entretiene y distrae también a sus protagonistas.

"Si te sientes aburrida te sientas a bordar [...]. Sólo me pongo a bordar y me distraigo" (Vivi, 24 años, entrevista personal, 21 de septiembre de 2009). ${ }^{2}$

Señalan algunas chicas que las mujeres jóvenes que son artesanas y no bordan con fines comerciales lo hacen para ocuparse y quienes bordan para uso personal lo realizan porque ocupan las prendas de vestir. Además, algunas mujeres consideran la importancia de este trabajo como un espacio que permite fortalecer vínculos sociales (especialmente familiares) ya que en ocasiones bordan juntas las hermanas, la madre, las hijas o las vecinas. Sobre esta cuestión interesa la dimensión afectiva que las mujeres le otorgan a las relaciones que entablan en el trabajo, y la más social relacionada con las posibilidades para la acción colectiva.

El trabajo artesanal realizado en compañía, generalmente con la madre, la hermana o alguna mujer de la familia, posibilita un espacio de comunicación y convivencia. La ejecución del trabajo con otras mujeres, une y genera lazos de confianza, unión y amistad.

Conviene también mencionar que diversos estudios han confirmado la importancia del trabajo en la realización de una actividad (Jahoda, Lazarsfeld y Zeisel, 1933/1972). En términos generales, mantenerse activo y ocupado es una de las principales motivaciones para trabajar, y uno de los mayores costes psicológicos de no hacerlo es la inactividad (Álvaro, 1992; La Fuente, 2008). El trabajo artesanal cumple esta función. Además de que distrae y entretiene a quienes lo realizan.

\section{Efecto terapéutico: Catarsis y estado de ánimo}

La producción de artesanías también tiene un efecto que podíamos llamar "catártico" al liberar de tristezas y de sensaciones desagradables a las artesanas. Dicen algunas mujeres que realizan este trabajo porque "disminuye la tristeza".

\footnotetext{
${ }^{2}$ Con el objetivo de respetar el anonimato y la confidencialidad de las personas que participan en este estudio, en los fragmentos de entrevista se colocan seudónimos.
} 
Algunas chicas indican que tiempo hubo en el que atravesaban dificultades personales y para disminuir la tristeza y la preocupación se dedicaban a bordar.

"(Bordar) Me distrae. Bordo para quitar un poco la tristeza y (para) liberarme de algo" (Eva, 22 años, entrevista personal, 28 de octubre de 2009).

"(Bordo) porque así olvido los problemas [...]. Me olvido de todo lo que hay" (Orli, 18 años, entrevista personal, 08 de septiembre de 2009).

Dígase también que para algunas mujeres realizar textiles es fuente de felicidad. En este sentido, literalmente defienden:

La felicidad me llega por mi trabajo. Siento alegría y felicidad. Me siento dichosa y orgullosa de mí misma por mi trabajo. [...] Cuando yo me pongo a trabajar me pongo feliz. Me hace feliz estar bordando. [...] La alegría la llevo en el corazón cuando trabajo. Me siento feliz y contenta al trabajar. Al momento de bordar siento alegría y me hace sentir feliz trabajar en las artesanías (Alondra, 18 años, entrevista personal, 12 de octubre de 2009).

\section{Fuente de satisfacción y orgullo}

El trabajo artesanal también es fuente de satisfacción y orgullo. Conviene, en este sentido, recurrir a Sennett (2009) quien nos habla de la motivación básica del artesano de lograr un trabajo bien hecho por la simple satisfacción de conseguirlo.

Una de las funciones psicosociales del trabajo artesanal que señala este autor es el orgullo por el trabajo propio y la satisfacción personal por el desarrollo de las habilidades. El trabajo artesanal no sólo permite, pues, desarrollar habilidades, destrezas y aplicar conocimientos sino también la ejecución de éstas genera satisfacción y orgullo a quien los realiza. Por eso, dice Sennett (2009) que la simple imitación no produce una satisfacción perdurable; la habilidad tiene que evolucionar y lleva consigo el sello personal y la imaginación de las artesanas. Pues, "la creatividad es también diferenciación" (Greenfield, 2004, p. 119), y motivo de orgullo, satisfacción y entusiasmo.

Muy importante es para mí ser artesana pues es el orgullo de ser mexicano. Es el orgullo de mi familia y de todos los de acá (de la comunidad). Me siento orgullosa por trabajar artesanías en esta comunidad y como los demás (jóvenes) no saben -y otros también quieren aprender- me siento dichosa de dominar esta habilidad. [...] Así salgo adelante y puedo apoyar económicamente a mi familia (Alondra, 18 años, entrevista personal, 12 de octubre de 2009).

Esta chica también reconoce que son pocas las jóvenes quienes en la comunidad saben y practican el conocimiento artesanal, este "saber-hacer" es referente capaz de otorgarle un valor a esta joven artesana y le proporciona una imagen positiva, al menos en relación con otras jóvenes "que no saben o que no aprendieron" el oficio. Su situación de artesana poseedora de conocimientos ancestrales le proporciona una identidad positiva, en tanto que la sitúa en una situación privilegiada en relación a sus coetáneos que no poseen dichos conocimientos. Además de que le otorga una imagen de utilidad comunitaria. 
"El orgullo por el trabajo propio anida en el corazón de la artesanía como recompensa de la habilidad y el compromiso" (Sennett, 2009, p. 361). En este sentido, hay que subrayar que lo que más enorgullece a los artesanos, como ya se ha dicho, es el desarrollo de sus habilidades. Además, la producción de artesanías, a través de su carácter instrumental, genera satisfacción y orgullo porque permite contribuir a la economía familiar. Este orgullo por el trabajo textil no se encontró en muchas mujeres, únicamente estuvo presente en el discurso de dos chicas: Alondra y Maricela. Ésta última más que al oficio artesanal defiende y promueve el orgullo de ser una mujer indígena.

Maricela considera que las instituciones educativas han tenido una participación importante en la revalorización de la cultura de los pueblos originarios. Esta joven se siente orgullosa de sus raíces indígenas, por esta razón defiende que para ella ser una mujer indígena es:

Cosa bonita. [...] Me siento bien, yo me siento orgullosa porque a pesar de que soy indígena he salido adelante. Bien o mal pero estoy aquí parada y sigo en pie. Por eso, mujer indígena es (sinónimo) de que todo se puede (Maricela, 24 años, entrevista personal, 09 de octubre de 2009).

Entre las mujeres de esta comunidad prevalece, lo que ya antes habían observado Godoy, Stecher y Díaz (2007), la búsqueda del bienestar del grupo familiar, y de una mezcla entre el trabajo como instancia de sacrificio pero también de orgullo, que se cristaliza en la imagen de la mujer que todo lo puede.

\section{Estructura el tiempo}

Otra función del trabajo artesanal es el establecimiento de una rutina, a la vez que estructura el tiempo de los habitantes de La llusión. No hay horarios ni duración establecida para sentarse a trabajar, sin embargo, con frecuencia se realizan textiles después de las actividades del hogar.

La mayoría de artesanas se dedica a este oficio todos los días y sus horarios son flexibles. Giddens (1991/1995) recuerda el valor fundamental de la costumbre en las prácticas sociales y en la autocomprensión; probamos pues alternativas sólo en relación con hábitos que ya hemos dominado. Imaginar una vida "de impulsos momentáneos, de acciones a corto plazo, desprovista de rutinas sostenibles, una vida sin hábitos, es, en el fondo, imaginar una existencia sin sentido" (Sennett, 2000, p. 45). Y es el trabajo en esta comunidad el generador de dicho sentido y de la estructuración del tiempo.

\section{Permite convivencia y unión familiar}

Las artesanas celebran también la flexibilidad que tienen en los tiempos de trabajo y, especialmente, disfrutan la independencia que tienen en la elección de colores y en los diseños que bordan en sus textiles, y las piezas que elaboran con ámbar. Además, la ejecución de este trabajo permite que se genere un espacio donde se fortalecen los vínculos familiares.

En torno a las artesanías se teje un sistema de relaciones familiares y tradiciones "en el que tiene lugar la enseñanza ancestral tanto ética, como técnica y desde luego espiritual” (Pérez, 2010, p. 2). El espacio de trabajo es el propio hogar y la convivencia e interacción con personas fuera del núcleo familiar, vecinal o comunitario no parece necesaria para la elaboración de artesanías. 
Lo que hay que subrayar a este respecto es que, más que fortalecer o fomentar la convivencia con otras personas, intercambiar experiencias, compartir afectos y opiniones con personas externas a la familia (como lo proponen Godoy et al., 2007), el trabajo artesanal fortalece los vínculos dentro del núcleo familiar. Al compartir el hogar y el taller el mismo espacio, realizar artesanías permite la convivencia entre los integrantes de la propia familia.

Así, el taller, que por su riqueza constituye un espacio colectivo de trabajo y rico en herramientas (Parias, 1965), implica un clima social, a la vez que al ser también hogar constituye un espacio de intimidad vecinal y familiar. Se observa, con esto, que la producción de artesanías no amplía necesariamente el ámbito familiar y vecinal sino más bien fortalece los vínculos de convivencia, confianza y comunicación dentro de éstas.

En la mayoría de los casos, en la elaboración de artesanías y en otros tipos de trabajos de la comunidad se observa esta función integradora de convivencia familiar y comunitaria del trabajo. Trabajar en conjunto como a veces sucede con las bordadoras, y quizá con mayor frecuencia con las ambareras, supone entablar conversaciones y generar un ambiente de confianza y de reciprocidad de información. Se fomenta así los vínculos afectivos en el núcleo familiar y vecinal.

Algo más hay que añadir. Como sucede en trabajos realizados en términos contractuales, gran parte de la vida social, como indica Giddens (1991/1995), se lleva a cabo en actividades impersonales, en ámbitos alejados del individuo corriente y sobre los que éste tiene poco o ningún control. La huida hacia la intimidad es un intento de garantizar una vida con sentido en medios familiares que no han quedado incorporados a estos sistemas amplios. La búsqueda de intimidad (que sí posibilita la producción de artesanías), tiene un valor positivo. "La privacidad posibilita las satisfacciones psíquicas que el logro de la intimidad puede ofrecer" (Giddens, 1991/1995, p. 122), y el trabajo artesanal propicia esta intimidad y otorga los beneficios psicosociales de ésta.

Además, la importancia de contar con relaciones personales íntimas tiene diversas funciones. Tal vez la función más importante, nos dice Cochrane (1992), que desempeñan este tipo de relaciones es la de propiciar una fuente intensa de satisfacción y de sentimientos positivos sobre la propia personalidad. Pertenecer a un grupo familiar es una parte importante de la identidad ya que constituye el primer vínculo relacional y el primer ámbito de interacción desde donde el individuo pasa a ser reconocido como parte integrante de un grupo. Reconocer y ser reconocido como hijo, como miembro de un grupo y como parte de una familia tiene una gran importancia para la construcción de la identidad del individuo (La Fuente, 2008). Vemos así constatado que, en el caso de las artesanías, el trabajo "une familia y trabajo" (Sennett, 2009, p. 83) y que el textil es sinónimo de hogar (Mejía, 2010).

\section{Permite permanencia y unión comunitaria}

Al ser este trabajo realizado en casa y dentro de la familia también permite la unión y la permanencia en la comunidad. Para ser artesano no es necesario salir o abandonar la comunidad porque "trabajo hay mucho en el cafetal, en el campo, en el taller y en el hogar" pero "dinero hay poco" y para ganarlo sí que ha sido necesario salir de ella. 
Algunas chicas prefieren quedarse en la comunidad y no consideran la posibilidad de dejarla pues implica "un cambio de pensamiento" y no quieren cambiar su forma de vida y de trabajo. Sea como fuere, para seguir siendo artesana no es necesario abandonar La llusión.

Además, este trabajo permite formar un "nosotros" que no necesariamente tiene que ver con la geografía pues ésta se refiere tan sólo al lugar. El trabajo en esta comunidad permite crear un sentido de comunidad que evoca dimensiones sociales y personales. Así, el lugar se vuelve comunidad cuando la gente "utiliza el pronombre "nosotros". Hablar así "requiere un apego personal, no geográfico" (Sennett, 2009, p. 144). Y el trabajo aquí (en La llusión) fomenta, construye y reafirma ese "nosotros".

\section{Expresión de la cosmovisión: hacer visible lo "invisible"}

El trabajo artesanal es también un medio de expresión de la cosmovisión de sus hacedoras. Realizada como expresión pública de la cosmovisión y la historia de los pueblos las artesanías son un fenómeno de continuidad histórica y son también un trabajo donde sus productores transforman y sobreviven, y lo que producen habla de estilos de vida, de cultura y de identidades (Novelo, 2010).

Para los fines de este argumento se debe subrayar que a partir del tejido las artesanas nos comparten su visión del mundo y el comportamiento cultural de sus comunidades. Las figuras de los tejidos y sus significados, no se tratan únicamente de la reproducción de determinada tipología sino de un ordenamiento de la naturaleza y el cosmos. Símbolos de la comunidad, la vida, el cielo, la tierra, el agua, la fertilidad, etc., nos dice Morales (2000), es lo que bordan las mujeres artesanas de Chiapas. El universo simbólico, arguye también este antropólogo, deviene indispensable para el desarrollo sano de los pueblos. Por eso, se indica que los textiles permiten que sobreviva la cultura (Morris, 1993) y que sea un bosque de símbolos donde emerge la profundidad cultural hasta nuestros ojos (De Orellana, 1993). La artesana, pues, agradece la libertad que tiene para crear, para inventar, para plasmar, para transformar y hacer visible lo invisible.

\section{Permanencia de la tradición}

La función anterior tiene que ver con la que se detalla a continuación: la permanencia de la tradición. A este respecto, Pérez (2010) indica que el objeto artesanal es, por muchas razones y de muchas maneras, ocasión de contacto humano no sólo en el sentido de que los objetos son el centro de la actividad comercial, una actividad comunicativa por excelencia. Sino en el sentido de que el objeto artesanal es el centro de la cohesión generacional por la que la generación mayor lega a la generación joven sus secretos al paso que lleva a cabo el ritual más estrecho de vinculación generacional en forma de una muy interna e intensa enseñanza generacional por la que se transmite el saber ancestral.

Las artesanías así entendidas son parte de procesos intensos de comunicación por los que se transmiten las tradiciones más íntimas de un grupo humano. Este es el sentido, nos dice Pérez (2010), más profundo de las artesanías: reafirmar la tradición y asegurar la cohesión generacional. Las voces de las artesanas en este sentido defienden que quieren que "siga viva la tradición":

Porque nuestros padres que vivieron antes también lo trabajaron y utilizaban las artesanías, con eso vivieron. Así consiguieron cosas de comer gracias al trabajo y por eso también me siento orgullosa de ser mexicana y aprender a bordar. La verdad, no, 
no sé, me llama mucho la atención porque también los demás (nuestros ancestros, nuestros abuelos), los que ya no viven, dejaron una herencia: el bordado. Es ahí donde me da más alegría recordar (a través de mi trabajo) a los que ya no están, (a) los que trabajaron así. [...] Los que vivieron antes trabajaron igual, por eso quiero seguir siendo artesana para sentirme también orgullosa de mí misma. [...] Bordar es heredar lo que mis padres y mis abuelitos son [...] (Alondra, 18 años, entrevista personal, 12 de octubre de 2009).

Algunas bordadoras, "se sienten portadoras de un mundo rico, de un mundo que viene de muy lejos en el tiempo. Al mismo tiempo que se saben creadores de las nuevas formas de esa tradición" (De Orellana, 1993, p. 53). Ven también jóvenes ambareros a las artesanías como un elemento que habla de tradición y como elemento cultural que liga a la comunidad con su pasado y con sus orígenes.

Como se ha visto hasta aquí, los textiles de Chiapas hablan de historias antiguas y modernas y de múltiples motivos que permiten su realización.

\section{Una propuesta de las funciones psicosociales del trabajo artesanal indígena}

He aquí que debe presentarse el siguiente diagrama (ver figura 1) que cumple con el objetivo principal de esta investigación: Conocer, describir y analizar las funciones psicosociales del trabajo artesanal indígena.

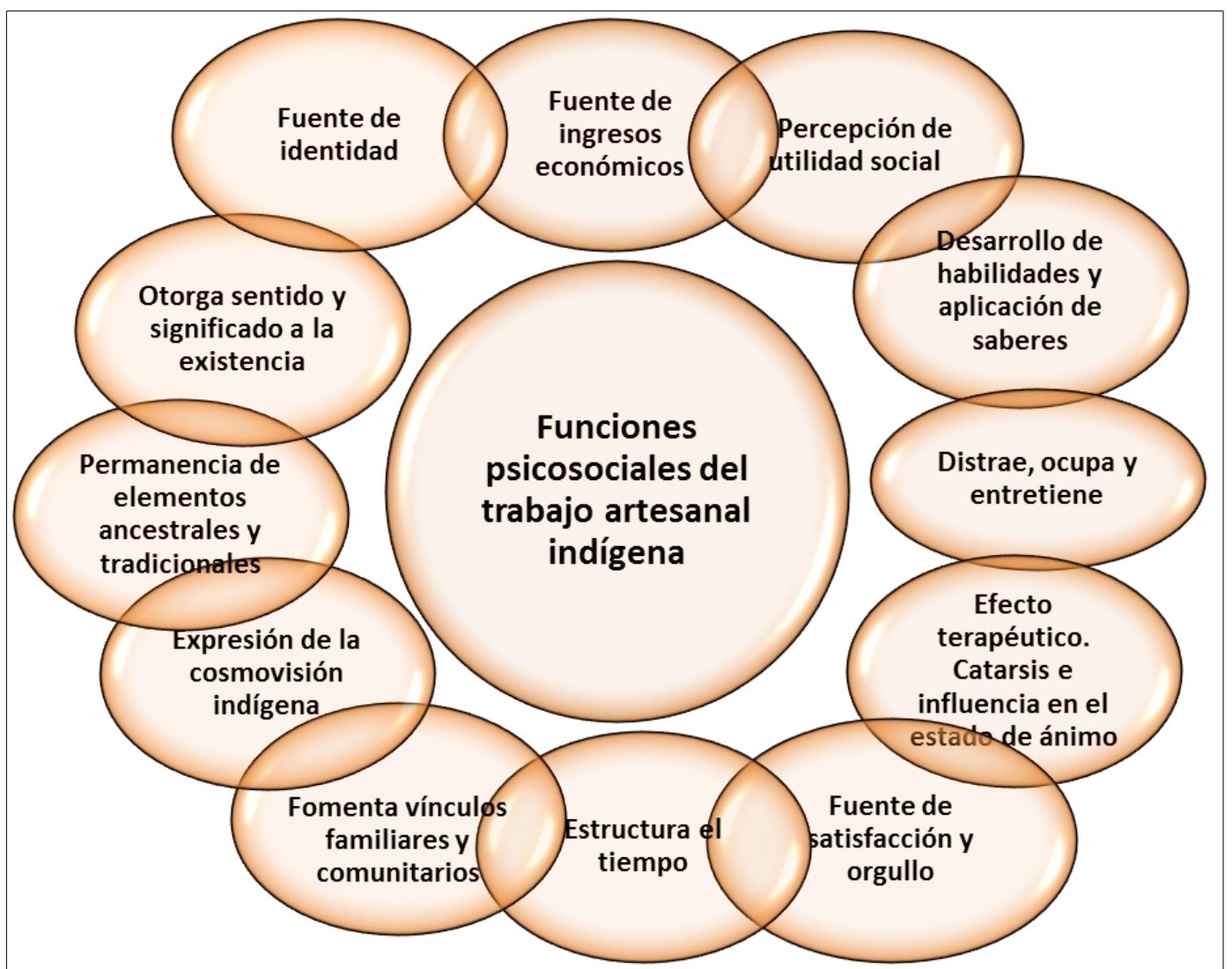

Figura 1. Diagrama de las funciones psicosociales del trabajo artesanal indígena.

Fuente: Elaboración propia a partir del contenido del trabajo de campo y el análisis realizado en el software Atlas.ti. 


\section{Reflexiones finales}

Hablar de las funciones psicosociales del trabajo artesanal es hablar de aspectos y beneficios (materiales e inmateriales) que tienen que ver con la transformación de materias primas, con tiempos de trabajo, con esfuerzo, con historias de dolor, de austeridad, de pobreza, de cosmovisión, de alegría, de tristeza, de orgullo, de tradición, de satisfacción, de necesidad, de globalización, de ocio y también de bienestar psicológico.

Los principales problemas del gremio, como se expone y argumenta en la versión completa de la tesis, tienen que ver con aspectos tales como: la precariedad económica de los productores, la comercialización de los productos, la intermediación, los bajos precios, la competencia con productos industriales y otras dificultades relacionadas con la necesidad de mayor organización, comunicación y acuerdo entre los integrantes del gremio.

Temas son todos estos que provocan migración, disminución de personas dedicadas a las artesanías y poco interés por aprender, enseñar y fomentar los saberes artesanales entre las nuevas generaciones. $Y$ si hablamos de artesanos indígenas este contexto resulta más difícil pues enfrentan una doble discriminación. Este sector, por ser artesanos y por ser indígenas, sufre una serie de desventajas y situaciones que obedecen, entre otras varias cosas, a las condiciones estructurales de la sociedad.

De ahí también que podamos decir que La llusión es una comunidad en la que se constata que para que el individuo construya su identidad necesita identificarse y diferenciarse con aquello que afectivamente le gratifica y satisface. Además, también necesita adscribirse a categorías a las que considere valiosas y portadoras de valor. Necesita, entonces, reconocerse y ser reconocido como alguien que tiene valor y ser catalogado como alguien socialmente significativo. Esto es así porque en esta comunidad, como probablemente también sucede en otros rincones del país, pareciese que para acceder a mejores condiciones del mercado del trabajo los pequeños productores tienen que construir una nueva imagen y una nueva forma de ser indígena.

A pesar de lo anterior, se constata aquí que realizar artesanías cumple con múltiples funciones psicosociales, tales como: Es fuente de ingresos económicos, permite el desarrollo de habilidades, destrezas y saberes; implica el desarrollo de una actividad que distrae, ocupa y entretiene a quien lo realiza; tiene un efecto terapéutico al permitir "catarsis" emocional e influye en el estado de ánimo de quienes lo realizan.

Realizar artesanías es también fuente de satisfacción y orgullo, estructura el tiempo y permite la independencia del artesano a la hora de elegir colores, diseños, formas y tiempos de trabajo. Fomenta además convivencia y unión familiar. No es eso todo. El trabajo artesanal también fomenta la permanencia y la unión comunitaria al ser un trabajo que no necesariamente implica salir o dejar el pueblo. Dígase también que es un espacio para la expresión de la cosmovisión y la permanencia de la tradición familiar y comunitaria, entre otras funciones.

La llusión constituye, pues, un caso emblemático de cómo las artesanías, lejos de ser productos determinados exclusivamente por la "tradición" son objetos cuyas características se asocian con una multiplicidad de factores diferenciados pero interrelacionados; factores que hacen subrayar el carácter dinámico y dialéctico de las artesanías. Viven en un clima de cambios y permanencias. Es así como deben ser vistas: como cambiantes. 
Hasta aquí, el largo recuento de la situación artesanal en la comunidad de estudio permite proponer a las artesanías como espacio, oportunidad y proceso que permite reproducir formas de vida que adoptan particularidades según las realidades socioeconómicas, personales y culturales de sus protagonistas.

Para concluir hay que señalar que falta mucho por estudiarse, investigarse y analizarse respecto a este trabajo que co-existe con otras formas de producción y que cumple con una serie de aspectos positivos que influyen en el bienestar psicológico de quienes lo realizan. Hay que ver, comprender y estudiar a las artesanías como la expresión de la diversidad, es decir, como expresión de las diferentes maneras en que las sociedades rurales están pudiendo o no, combinar sus tradiciones, habilidades, representaciones, significados y tensiones con los impulsos de la globalización.

\section{Referencias}

Agulló, Esteban (1997). Jóvenes, trabajo e identidad. Oviedo: Universidad de Oviedo.

Álvaro, José Luis (1992). Desempleo y bienestar psicológico. Madrid: Siglo XXI.

Álvaro, José Luis (2003). Fundamentos sociales del comportamiento humano. Barcelona: UOC.

Balazote, Alejandro \& Rotman, Mónica (2006). Artesanías Neuquinas: Estado y comercialización de artesanías mapuche. Revista Theomai. Estudios sobre Sociedad, Naturaleza y Desarrollo, 14, $58-65$.

Blanch, Josep M. (1986). Desempleo juvenil y salud psicosocial. Documentos de psicología social. Barcelona: Universidad Autónoma de Barcelona.

Cardini, Laura (2007). Reflexiones que convergen: aproximaciones a la producción artesanal indígena en la ciudad de Rosario. En Mónica Rotman, Juan Carlos Radovich \& Alejandro Balazote (Ed.), Pueblos originarios y problemática artesanal: procesos productivos y de comercialización en agrupaciones mapuches, guaraní/chané, wichís/tobas y mocovíes (pp. 251-270). Córdoba, Argentina: Universidad Nacional de Córdoba.

Cochrane, Raymond (1992). Incidencia de la depresión en hombres y mujeres. En José Luis Álvaro; José Ramón Torregrosa \& Alicia Garrido (Ed.), Influencias sociales y psicológicas en la salud mental (pp. 49-71). Madrid: Siglo XXI.

De Orellana, Margarita (1993). Voces entretejidas. Testimonios del arte textil. Artes de México, 19, 43-59.

García Canclini, Néstor (1982/1986). Las culturas populares en el capitalismo. México, D.F.: Nueva imagen.

Giddens, Anthony (1991/1995). Modernidad e identidad del yo. El yo y la sociedad en la época contemporánea. Barcelona: Península.

Godoy, Lorena; Stecher, Antonio \& Díaz, Ximena (2007). Trabajo, identidades: continuidades y rupturas en un contexto. En Rocio Guadarrama \& José Luis Torres (Ed.), Los significados del trabajo femenino en el mundo global (pp. 81-100). México D. F.: Anthropos y Universidad Autónoma Metropolitana. 
Greenfield, Patricia (2004). Tejiendo historias. Generaciones reunidas. Nuevo México: School of American Research Press.

Hendrick, Ives (1943). Work and the pleasure principle. Psychoanalitic Quarterly, 12, 311-329.

Jahoda, Marie; Lazarsfeld, Paul \& Zeisel, H. (1933/1972). Marienthal: The sociography of an unemployed community. Nueva York: Aldine-Atherton.

La Fuente, María Isabel (2008). Identidad laboral y transformaciones del mercado de trabajo: Un análisis desde el discurso de los jóvenes bolivianos. Tesis de doctorado. Universidad Complutense de Madrid.

Mejía, Diana (2010, octubre). Tejiendo la vida: significados de la tradición textil en la sierra de Zongolica. Aportaciones al estudio semiótico de la cultura mexicana. Comunicación presentada en XXXII Coloquio de antropología e Historia Regionales, Zamora, Michoacán, México.

Morales, Jesús (2000). Literatura, ritualidad y artesanías. En Victoria, Novelo (Ed.), Artífices y artesanías de Chiapas (pp.138-193). México, D.F.: CONACULTA/CONECULTA.

Morris, Walter (1993). Simbolismo de un Huipil ceremonial. Artes de México, 19, 65-74.

Muñoz, Juan (2005). Manual de Análisis cualitativo de datos textuales con Atlas.ti. Extraído el 15 Febrero de 2009, de http://www.ugr.es/ textinfor/documentos/manualatlas.pdf

Novelo, Victoria (1976). Artesanías y Capitalismo en México. México: SEP/INAH.

Parias, Louis-Henri (1965). Historia general del trabajo. Barcelona: Grijalbo.

Pérez, Herón (2010). El sentido de las artesanías en el concierto de la cultura. Comunicación presentada en el XXXII Coloquio de antropología e Historia Regionales, Zamora, Michoacán, México.

Rotman, Mónica (2001). Cultura y mercado. Estudios Antropológicos sobre la problemática artesanal. Buenos Aires: Minerva.

Rotman, Mónica (2002). Problemática artesanal indígena. Procesos productivos y de comercialización: un análisis comparativo de grupos Mapuche, Chané y Wichi. Buenos Aires: Agencia Nacional de Promoción Científica y Tecnológica.

Rotman, Mónica (2007). Prácticas artesanales: procesos productivos y reproducción social en la comunidad Mapuche Curruhuinca. En Mónica Rotman; Juan Carlos Radovich \& Alejandro Balazote $(\mathrm{Ed}$,$) , Pueblos originarios y problemática artesanal: procesos productivos y de$ comercialización en agrupaciones mapuches, guaraní/chané, wichís/tobas y mocovíes (pp.4169). Córdoba, Argentina: Universidad Nacional de Córdoba/CONICET.

Ruiz, José Luis \& Trejos, Marisa (2000). Los textiles y los tejidos de Chiapas. En Victoria, Novelo (Ed.), Artífices y artesanías de Chiapas (pp. 194-249). México, D. F.: CONACULTA/CONECULTA.

Sanchis, Enric (1991). De la escuela al paro. Madrid: Siglo XXI.

Sennett, Richard (2000). La corrosión del carácter. Barcelona: Anagrama. 
Sennett, Richard (2009). El artesano. Barcelona: Anagrama.

\section{Formato de citación}

Del Carpio Ovando, Perla Shiomara (2012). Entre el textil y el ámbar: las funciones psicosociales del trabajo artesanal en artesanos tsotsiles de la ilusión, Chiapas, México. Athenea Digital, 12(2), 185-198. Disponible en

http://psicologiasocial.uab.es/athenea/index.php/atheneaDigital/article/view/DelCarpio

Este texto está protegido por una licencia Creative Commons.
Usted es libre de copiar, distribuir y comunicar públicamente la obra bajo las siguientes condiciones:
Reconocimiento: Debe reconocer y citar al autor original.
No comercial. No puede utilizar esta obra para fines comerciales.
Sin obras derivadas. No se puede alterar, transformar, o generar una obra derivada a partir de esta obra.
Resumen de licencia - Texto completo de la licencia

